\title{
Multidisciplinary Teamwork and the Insanity Defence: A Case of Infanticide in Iraq
}

\author{
Hasanen Al-Taiar
}

\subsection{Introduction}

Capital punishment still exists in many countries and mainly in the Middle East where Islam is the main formal religion for most states.

Here, the author describes the case of a young woman from Iraq who was arrested by Police on suspicion of murdering her 1-year-old son. Due to concerns about her mental state, it was decided that she would appear before a specialist panel of experienced mental health professionals in the main psychiatric hospital in Baghdad, Iraq. This panel was comprised of consultant psychiatrists, psychologists and nurses whose specialism is in dealing with forensic psychiatric cases. The author has sought consent from the patient who was willing for her case to be discussed for clinical and academic purposes.

\subsection{Narrative}

The author visited Al-Rashad psychiatric Hospital in Baghdad in April 2018 and he was impressed by the work of the forensic psychiatry committee that determines the criminal responsibility of a large number of cases from all over Iraq. One case that drew a lot of attention was that of a young woman (23) who allegedly killed her 1 yearold infant by dropping the mattresses and blankets over him. The professional committee consisted of specialist psychiatrists (three to four) in addition to psychiatric nurses and psychologists. It met on two occasions to determine the defendant's criminal responsibility. Potential disposals could be admission to a psychiatric hospital via a Court order should she be found "not guilty as a result of insanity". Alternatively, she could still face capital punishment if she was found guilty of committing the offence.

\footnotetext{
H. Al-Taiar $(\bowtie)$

Oxford Health NHS Foundation Trust, Littlemore Mental Health Centre, Oxford, UK

(C) The Author(s) 2021

D. Stoyanov et al. (eds.), International Perspectives in Values-Based Mental

Health Practice, https://doi.org/10.1007/978-3-030-47852-0_17
} 
This patient appeared twice before the panel and it was agreed that she was having a form of a neurodevelopmental disorder i.e. autism and she was intellectually challenged. In addition, she showed some psychotic symptoms e.g. auditory hallucinations commanding her to kill her son to protect her safety. She married at the age of 22 to a local man in her village. She lived with her husband and mother in law. One day, she was cleaning her bedroom and alleged that she mistakenly dropped the duvets on her 1 year old son who suffocated and died shortly afterwards. She was arrested by Police where concerns were instantly raised about her mental welling hence the referral to the criminal panel at Al-Rashad Hospital.

During the two interviews, the lady in question didn't present with obvious signs of a psychotic disorder but was rather showing features of a possible autistic disorder. The panel examined the clinical notes and the criminal case summary (Police and Court documents) over a number of weeks prior to and in between these two interviews.

The conclusion was that this young lady was exhibiting features suggestive of a possible autistic spectrum disorder and a learning disability which would require further assessment. Autism is characterized by qualitative abnormalities in reciprocal social interactions and in patterns of communication, and by restricted, stereotyped, repetitive repertoire of interests and activities [1]. In addition, patients with autistic spectrum disorders have a restricted, repetitive, and stereotyped patterns of behaviours, that could manifest as "compulsive adherence to specific, nonfunctional routines/encompassing preoccupation with one or more stereotyped and restricted patterns of interest that are abnormal in content or focus; or abnormal in their intensity". This could explain his lack of flexibility around not wearing the used boots. Some patients with autism will exhibit Stereotypy or self-stimulatory behaviour which refers to repetitive body movements or repetitive movement of objects. This behaviour is common in many individuals with developmental disabilities; however, it appears to be more common in autism. Many autistic people have intense and highly-focused interests, often from a fairly young age. These can change over time or be lifelong. Although repetitive behaviour varies from person to person, the reasons behind it may be the same e.g. an attempt to gain sensory input, e.g. rocking may be a way to stimulate the balance system. In the same way, using the phone could provide sensory/auditory stimulation. Such repetitive behaviours can occur to deal with stress and anxiety and to block out uncertainty. Such patients can be supported via modifying their environments, increasing structure or managing their anxieties.

The panel concluded that the patient's behaviour was not calculated to cause annoyance and inconvenience, but rather a symptomatic feature of her possible autistic disorder to the extent that it displays a compulsive adherence to specific, non-functional routines, abnormal in content, focus, and intensity.

In a country like Iraq where Islam is the main formal religion which the majority of population practice, capital punishment is still seen as one of the most ethically challenging prospects. Iraq witnessed many military conflicts over the last four decades and these have eroded the infrastructure of the Iraq economy in addition to the loss of many people (civilians and military). Obviously the criminal 
responsibility panel has a huge responsibility as it determines life pathways for most offenders who come in contact with it. Its decision could mean that the suspect would face a punitive outcome e.g. custody, execution or a less adversarial outcome such as psychiatric treatment (initially in hospital). Where mental illness is still seen as a stigma in many areas of Iraq especially rural and less urbanized ones, it would undoubtedly be more favourable in the families of their affected ones.

\subsection{Cultural Context}

Ancient Iraq (Mesopotamia) witnessed the first mention of the Insanity Defencein the Hammurabi's code that dates back to around 1772 BC [2]. Today, with Islam as the main formal religion (and practiced by the majority of the population), capital punishment is still seen as one of the most ethically challenging prospects.

Iraq witnessed many military conflicts over the last four decades, and these have eroded the infrastructure of the Iraq economy in addition to the loss of many people (civilians and military). Obviously, the criminal responsibility panel has a huge responsibility as it determines life pathways for most offenders who come in contact with it. Its decision could mean that the suspect would face a punitive outcome, e.g. custody, execution or a less adversarial outcome such as psychiatric treatment (initially in hospital). Where mental illness is still seen as a stigma in many areas of Iraq especially rural and less urbanized ones, it would undoubtedly be more favourable in the families of their affected ones.

\subsection{The Criminal Responsibility Panel as a Multidisciplinary Team}

The Criminal Responsibility Panel is a specialist team of professionals employed by the Ministry of Health, and they have a close link with the judicial system in which all cases of suspected psychiatric morbidity would be referred to them by the Police or Court. The remit of this panel is to establish the presence or absence of a mental disorder and then recommending any suitable disposals in line with the severity of the offence and the mental disorder.

The panel is set up to meet in the hospital once weekly for a full day when they assess all remanded detainees who are escorted by Police or prison staff.

The panel is chaired by a senior consultant psychiatrist who is assisted by 2-3 other specialists, trainee psychiatrists, in addition to other disciplines such as psychology and nursing.

Obviously, each case is assessed individually and professionals discuss them in huge detail to ascertain criminal responsibility. Two elements are examined here, actus reus (criminal act) and mens rea (criminal intent) [3].

The panel demonstrates a very good model of multidisciplinary team (MDT) work in such a politically sensitive matter. Professionals themselves might find it a challenging task to separate their own personal lives from undertaking their duty 
especially in the current political uncertainty. Over the last four decades, Iraqis have witnessed a number of military conflicts where millions of souls have been lost to violence. A culture of violence started to prevail among Iraqis in 1980, and an instinct for aggression began to rise in the collective subconscious of the people.

The panel takes in consideration whether the patient was actually mentally ill or simply making up "malingering” or faking symptoms of mental illness for purposes of secondary gain, i.e. avoiding criminal proceedings and consequences such as capital punishment.

Dissociative disorders are also prevalent in countries like Iraq, and they often present with psychosomatic symptoms such as tiredness and generalized pains.

More knowledge about specific disorders and their management, e.g. culturebound syndromes which are psychiatric conditions, assumed to be specific to a particular culture, that has become the focus of an on-going debate in psychiatry and the social sciences, on the question of the primacy of either universal biopsychological or specific ethnic-cultural factors determining psychopathology.

The fall of the Baath leadership and change of power in 2003 brought with its further complications. Corruption has eroded the infrastructure of Iraq including political, industrial and cultural aspects. The psychological effect of this change resembled the exchange of roles between a master and slave. This reality is explained by the following theory: A society that has two large sects, where one acquires power with the help of external force and the other is subjected to political, economic and psychological frustration, creates sectarian strife. Such medico-legal panels have remained away from political pressures although in would argue that corruption has even invaded the health system. Health professionals especially doctors have been targeted by successive waves of abductions and murders which jeopardized the Iraqi medical community to a large extent. Many doctors have fled the country, relocated work and accommodation, or hired bodyguards for protection.

\subsection{Conclusions}

The case illustrates a good example of multidisciplinary and inter-agency work and collaboration. It focuses on a number of cultural issues such as stigma and mental illness especially in women. Many families keep their daughters' mental illnesses in a very discreet manner for fear of stigma. Many psychiatric patients experience stigma and discrimination from the society and sometimes from families, friends and employers. It is evident that discrimination and stigma have a detrimental influence on patients' lives. Such discriminatory experiences can also worsen patients' mental health problems and hinder their access to treatment recovery. Social isolation, poor housing, unemployment and poverty are all linked to mental ill health. Stigma and discrimination can trap people in a cycle of illness.

Acknowledgements The author would like to thank all staff members who assisted his visit to Al-Rashad Hospital, especially Dr. Ali Al-Amery (forensic department lead) and members of the criminal responsibility panel. 


\subsection{Guide to Further Sources}

http://applications.emro.who.int/dsaf/EMRPUB_2009_EN_1367.pdf

\section{References}

1. World Health Organization. International statistical classification of diseases and related health problem (ICD-10).

2. Downey M, Farhat F, Garofolo A, Jones R. History of forensic psychology; 2008.

3. Bronitt S, McSherry B. Criminal justice and procedure (LAW109). Macquarie University.

Open Access This chapter is licensed under the terms of the Creative Commons Attribution 4.0 International License (http://creativecommons.org/licenses/by/4.0/), which permits use, sharing, adaptation, distribution and reproduction in any medium or format, as long as you give appropriate credit to the original author(s) and the source, provide a link to the Creative Commons license and indicate if changes were made.

The images or other third party material in this chapter are included in the chapter's Creative Commons license, unless indicated otherwise in a credit line to the material. If material is not included in the chapter's Creative Commons license and your intended use is not permitted by statutory regulation or exceeds the permitted use, you will need to obtain permission directly from the copyright holder.

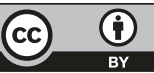

